\title{
Effects of Product Type and Recommendation Approach on Consumers' Intention to Purchase Recommended Products
}

\author{
Yi-Cheng Ku* \\ Department of Business Administration \\ Fu Jen Catholic University \\ New Taipei City, Taiwan (R.O.C.) \\ ycku@mail.fju.edu.tw \\ Yi-Ming Tai \\ Department of Information Management \\ National Pingtung University \\ Pingtung County, Taiwan (R.O.C.) \\ ymtai@mail.nptu.edu.tw \\ Chih-Hung Chan \\ Department of Computer Science and Information Management \\ Providence University \\ Taichung City, Taiwan (R.O.C.) \\ chan.vo519@gmail.com
}

\begin{abstract}
Many e-stores offer product recommendation services to increase sales and customers' satisfaction. However, previous studies indicate that the performance of recommendation systems may be influenced by consumers' perception of the recommended products, which may be affected by how the product was recommended. The purpose of this study is to investigate the effects of product type and recommendation approach on consumers' intention to purchase recommended products. A laboratory experiment was conducted to collect empirical data and ANCOVA was adopted to test our research hypotheses. We found significant interaction effects between recommendation approach and product type on consumers' intention to buy the recommended products and their disconfirmation of the recommended products. Before experiencing the products, consumers' purchase intention was significantly higher for search goods when they were recommended by the Top-N approach than when they were recommended by the collaborative filtering approach. After experiencing the products, however, consumers' disconfirmation was significantly higher for experience goods when they were recommended by the Top- $N$ approach than when they were recommended by the collaborative-filtering approach. Furthermore, the disconfirmation of experience goods was significantly higher than that of search goods when they were recommended by the Top-N approach. Our findings provide valuable insights into choosing product recommendation approaches for different types of products.
\end{abstract}

Keywords: Recommender systems, experience goods, search goods, purchase intention, electronic commerce 


\section{Introduction}

Electronic commerce and online shopping are penetrating our daily life. The variety and velocity of changing product information, along with high competition in the electronic channel, thus, force most online sellers to adopt systems that recommend relevant products to consumers (Zhang et al., 2011). Amazon.com is a pioneer in adopting recommendation systems for cross-selling based on their customers' purchasing history or browsing behaviors. Netflix is well-known for its precise video recommendation that earns high customer loyalty. These successful examples show the importance of product recommendation in electronic commerce.

Given the need for product recommendation, it is interesting to know how to increase the effect of recommendation and whether different recommendation approaches may perform differently. The techniques of product recommendation can be roughly divided into personalized and nonpersonalized recommendation techniques. For example, the Top- $\mathrm{N}$ approach that informs consumers with the best-selling items is a non-personalized technique because it does not use historical purchase information of specific consumers. Personalized recommendation, on the other hand, determines what to recommend based on individual customer's personal interests or prior purchase history. For example, the collaborative-filtering approach predicts a consumer's preference based on a group of consumers whose interests are similar to the target one and makes recommendation accordingly ( $\mathrm{Li}$ and Karahanna, 2015).

Prior research has indicated that consumers may behave differently when they purchase different products. This is understandable as decision processes are definitely different between ordering books and buying clothes. In other words, the nature of different products may be an important factor that affects the outcome of product recommendation. In marketing, physical goods can roughly be separated into search goods and experience goods (Nelson, 1970). Search goods mean that consumers are able to acquire complete or most information of the product's main properties before buying it (e.g., personal computers), while experience goods' main properties can only be evaluated after that was consumed. Also, its information acquisition is much more difficult than directly experiencing it (e.g., clothes).

The purpose of this research is to examine how different recommendation approaches may fit different products in order to improve the performance, which may be measured by consumers' intention to purchase the product and possible regrets after purchase. Purchase intention is a common measurement of the outcome of a promotion activity. In this study, we adopt an additional construct to evaluate the psychological feeling after experiencing recommended products. Consumers often experience a gap between their prior expectations and perceived performance after purchasing it (Venkatesh and Goyal, 2010). This is called "disconfirmation" or "experience gap." If consumers experience significant disconfirmation after buying the recommended product, it will affect their satisfaction of the recommendation mechanism and further influence their loyalty. As a result, it is important to also examine how different recommendation approaches and product types may affect consumers' disconfirmation after experiencing recommended products.

This paper is organized in the following way: we are going to explore related research literature in the next section. The research hypotheses and research methods are proposed in Section 3, and the findings and discussions are described in Section 4. A brief conclusion is made and managerial implications are offered in the last section. 


\section{Literature review}

\section{Recommendation System}

Recommendation systems (also known as recommender systems) generate personalized messages to persuade consumers to buy recommended products while surfing or shopping. They have been applied to many domains including electronic commerce, knowledge management, and many others (Xiao and Benbasat, 2007; Liang et al., 2008; Köhler et al., 2011). A recommendation system often provides product information to users based on user demographics, item features, and/or user preferences. Through this service, e-stores can increase sales, customer satisfaction and consumer loyalty (e.g., Liang et al., 2006; Chen et al., 2010; Zhang et al., 2011).

Many approaches have been developed for product recommendation. Some locate personalized product recommendation based on consumers' historical purchase history, while others make product recommendations from overall selling profile (i.e., non-personalized recommendation). The most widely used personalized recommendation approaches include attribute-based recommendation, item-toitem correlation, and people-to-people correlation (Schafer et al., 1999). The most popular non-personal recommendation approach is the Top-N (TN) approach that recommends the best-selling $\mathrm{N}$ product items. It does not put users' personal interests into consideration, but focuses on the general popularity of products. Every user receives the same recommendation information.

Personalized recommendation has many different methods. The attribute-based recommendation, also known as contentbased approach, chooses the recommended products based on the attributes of the products. Users have to specifically "tell" the system their needs so that similarity analysis of their needs and products' attributes can be learned and then the products that meet users' needs are recommended. Item-to-item correlation is based on the correlation between different products. For example, when a customer purchases coffee beans, usually he may also buy some sugar and coffee-mate. People-to-people correlation, also known as the collaborative filtering approach, is based on the preference similarity among users. Product preference of a group of users is identified based on their previous purchase data. Products of interest to the group are recommended if a new consumer is classified into the specific group ( $\mathrm{Li}$ and Karahanna, 2015).

From the perspective of consumers, the process of recommendation systems is a "black box" because they have little knowledge about how a product is recommended (i.e., the internal algorithm for recommendation). As a result, consumers evaluate recommendation service based on the descriptive information available to them (Wang and Benbasat, 2007). Recommendation information provided by e-stores includes personalized messages generated by the system to explain the basis (such as "those who viewed this product also bought ...") and non-personalized message related to the recommended product (e.g., product functionality). Similar to advertising, recommendation information informs and persuades consumers to be interested in and to buy the recommended product (Yu et al., 2011).

From the information processing perspective, consumers' purchase intention is influenced by their perception of the recommendation information. Consumers' perception will further determine consumers' buying decisions. In other words, consumers' understanding of the recommended product is influenced by both description of making the recommendation and product information. This implies that the description of the recommendation approach may influence the decision process and the purchase intention of the consumer. 


\section{Effect of Product Type on Online Shopping}

Another factor that may affect the process of purchase decisions is the nature of products. There are several different ways by which products can be differentiated. A popular one proposed by Nelson (1970) used product features to separate products into search goods and experience goods. Search goods mean that through collecting information, consumers are able to assess a product's quality or features before buying it (e.g., a USB disk), while experience goods mean their properties can only be evaluated after buying or consuming it (e.g., restaurant). Different types of products may create different levels of difficulty in evaluating whether a recommended product meets the need of a consumer. Prior research has found that different product types not only affect consumers' message processing but also influence their on-line shopping behavior. For instance, Mudambi and Schuff (2010) found that reviews of experience goods with extreme ratings are less helpful than reviews with moderate ratings, while review depth has a greater positive effect on search goods. Previous research also reported that online consumers are more willing to buy search goods (such as books) than experience goods (such as perfume) (Chiang and Dholakia, 2003). In another study, Gupta et al. (2004) found that online consumers were more willing to buy books and tickets (search goods) than wine and stereos (experience goods). Product type is considered an important factor that affects consumers' purchase decision (Im and Hars, 2001; Wang and Lin, 2003). Therefore, we need to take product type into consideration when we investigate the effect of product recommendation.

\section{Expectation Disconfirmation after Consumption}

While many studies have investigated the effect of product recommendation on consumers' purchase intention, it is also important to investigate the continuing effects after consuming recommended products. It is common that people intend to find a target to blame when the outcome of an event is worse than what they thought. Consumers may feel "disconfirmation" or unsatisfied when their experience with using the recommended product is worse than expectation. Based on the expectation disconfirmation theory, three possible situations may exist after consumption: when performance equals expectation, there is no disconfirmation; when performance exceeds expectation, positive disconfirmation takes place; when performance is worse than expectation, negative disconfirmation occurs (McKinney et al., 2002; Tan et al., 2016).

Before purchasing a product, consumers establish their performance expectations based on past experience. After the purchase, they compare product performance with their expectation to generate a positive or negative disconfirmation (Cadotte et al., 1987). If there is a gap between performance and expectation, the customer will change his rating of the product recommendation, their satisfaction and loyalty. Applying the theory to online product recommendation, consumers would build their expectations in the purchasing process and assess the performance while experiencing the product or service. In a study, Serenko and Stach (2009) reported that a positive expectation disconfirmation instills customer loyalty while a negative expectation disconfirmation decreases customer loyalty in online travel agents. Therefore, we believe that different recommendation approaches and product types affect the expectation and perceived performance of the recommended product, which may further affect their disconfirmation and loyalty.

\section{Research Hypotheses and Experiment Design}

The purpose of this research is to understand whether recommendation 
approach and product type will affect consumers' purchase intention and experience gap when they are shopping online. This study focuses on the comparison between non-personalized recommendation (the Top-N approach, TN) and the personalized collaborative-filtering (CF) approach. As for the effect of product type, we aim at comparing the recommendation effect of search goods and experience goods. In addition to the main dependent variable of consumers' willingness to purchase the recommended product, we also evaluated their disconfirmation after they actually consumed the product. That is, we evaluated the absolute value of the difference in purchase intention before and after they experienced the product. Research hypotheses and the experimental design will be described below.

\section{Research Hypotheses}

In a typical purchasing process, a consumer first searches for related product information. After comparing information and making judgment, the purchase intention is formed. Purchase intention means a consumer's subjective purchase tendency of a certain product. It has been proven to be an important indicator that can predict the actual purchase behavior (Fishbein and Ajzen, 1975). Purchase intention is also considered the possibility of a customer buying a certain product. The higher the purchase intension is, the greater the purchase possibility will be (Schiffman and Kanuk, 1999).

\section{(1) Effect of recommendation methods}

Previous research reported that subjects who consulted product recommendations selected recommended products twice as often as subjects who did not consult recommendations and that online recommendation was more influential than traditional ones, such as human experts (Senecal and Nantel, 2004), which indicates that consumers' purchase decision is affected by recommendation. As personalized recommendation takes individual preference into consideration and has been found to be useful in raising customer satisfaction (e.g., Liang et al., 2006), we expect that the purchase intention of products recommended by personalized recommendation approaches such as the CF method will be higher than that of the products recommended by nonpersonalized recommendation approaches such as the TN approach. Similarly, the products recommended by CF may meet consumers' expectation better than the products recommended by the TN approach. Therefore, we propose the following:

H1: Consumers' purchase intention of the products recommended by CF is higher than that of the products recommended by $T N$.

H2: Consumers' disconfirmation of the products recommended by CF is lower than that of the products recommended by TN.

\section{(2) Effect of product types}

The effects of product type on purchase intention are mixed. For example, Senecal and Nantel (2004) found that consumers would be more influenced by recommendations for experience products (wine) than for search products (calculator). On the other hand, consumers are found to be more willing to buy search goods than experience goods on-line, because they are able to recognize more about the features of search goods than experience goods before purchasing them (Chiang and Dholakia, 2003; Gupta et al., 2004). The reason that consumers are more likely to buy search products is probably due to the nature that it is more difficult to assess the value of information for experience products without actual experiencing the product. Hence, we posit the following hypotheses.

H3: Consumers' purchase intention of search goods recommended by recommendation systems is higher than that of experience goods.

H4: Consumers' disconfirmation of search goods recommended by recommendation 
systems is lower than that of experience goods.

\section{(3) Interaction Effects}

Since CF and $\mathrm{TN}$ are recommendation approaches based on different theoretical foundation and consumers may have different decision processes when they purchase search products and experience products, it is reasonable to assume that different recommendation approaches may be more suitable for different type of products. In other words, interaction effects may exist in online product recommendation. As the TN approach is primarily based on the tendency of following the crowd (also called the herd behaviour) while the CF approach focuses on individual idiosyncrasy, the former may be more suitable for experience products whose purchase decisions are not easily determined by product attributes but the latter may be more suitable for search products whose purchase decisions are more likely to be determined by product attributes. The interaction effect between recommendation methods and product types is supported by literature. For example, consumers evaluated recommendation agents more favourably for search goods than experience goods, and rule-based recommendations were preferred for search goods but not for experience goods. (Aggarwal and Vaidyanathan, 2005). Furthermore, consumer reviews were found to elicit higher perceived usefulness, trusting beliefs, and perceived affective quality for experience goods, while provider recommendations were found to unfold higher effects on all of these variables for search goods (Benlian et al., 2012). Hence, we posit hypotheses $\mathrm{H} 5$ and $\mathrm{H} 6$ :
H5: Recommendation approach and product type have significant interaction effects on consumers' intention to purchase recommended products.

H6: Recommendation approach and product type have significant interaction effects on consumers' disconfirmation of recommended products.

(4) Effect of personality

Since recommendations can be considered a process of persuasion, its effect may be moderated by consumer's personality. Different types of people generally have different ability to adapt their behavior to meet the changing environment. The concept of self-monitoring deals with the phenomena of expressive controls and indicates an ability to regulate behavior to accommodate social situations (Snyder, 1974). People with high self-monitoring are more likely to adjust their own behavior based on the social cues gathered from other people and social context, while low self-monitoring people are more controlled by their own internal states (i.e., beliefs, attitudes, and dispositions) and tend to maintain a consistent behavior model and ignore the environmental needs (Snyder, 1974 ; 1982). Applying the concept to the online shopping situation, consumers with different degrees of self-monitoring personality may react differently to product recommendation and have different levels of purchase intention. Since personality is not a variable we can manipulate, we treat consumers' self-monitoring degree as a covariate control variable. The research framework of this study is outlined in Figure 1. 


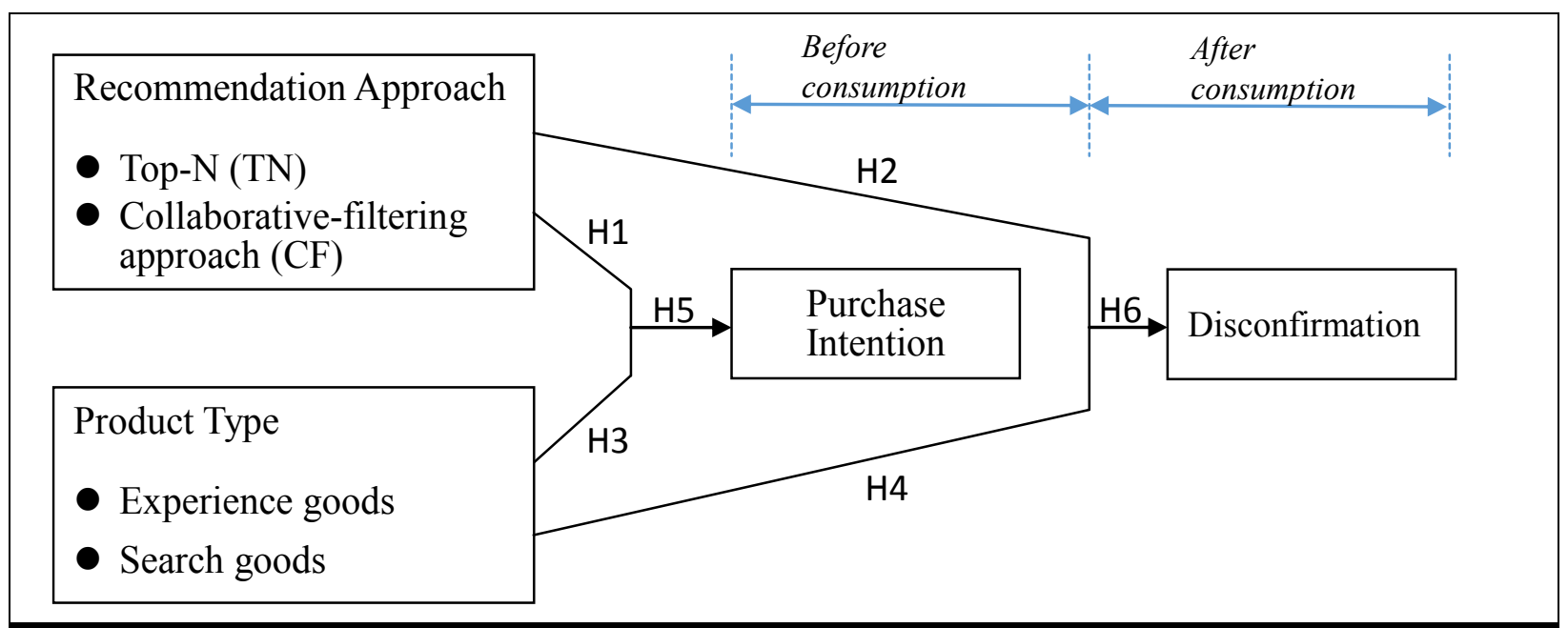

\section{Figure 1 - Research Model}

\section{Experiment Design}

A two-factor experiment was designed to test the hypotheses. Both recommendation approaches and product types are independent variables. Recommendation approaches are TN and CF, whereas product types are experience goods (healthy drink) and search goods (magazine). An experimental website was designed to deliver the experimental task (see Appendix 1 for sample screens of the website). Purchase intention and disconfirmation are dependent variables while the self-monitoring degree is the covariate. Three items adapted from previous studies were used to measure the purchase intention (Dodds et al., 1991; Grewal et al., 1998) and 18-item proposed by Snyder and Gangestad (1986) were used to measure self-monitoring (see Appendix 2 for the measurements).

The experiment was conducted in a laboratory to collect data. The advantage of laboratory experiment is that researchers are able to observe and evaluate manipulated variables' impact on dependent variables with minimal interference from other relevant factors. Comparing to the field experiment, the laboratory experiment provides higher internal validity and better control over the experimental process, but may be lower in external validity. Since the purpose of our study is to examine the effects of two independent variables and a better control of the experimental process to minimize possible pollution by other factors is very important, using the laboratory experiment is appropriate.

Volunteers were recruited from a university in Taiwan. All subjects had to fill out questionnaires to provide their product preferences at their registration for the experiment. A total of 108 subjects joined the experiment. The experimental process includes two major modules: one before the purchase and the other one after the purchase. The following are major steps:

Step 1: The subject was given instructions for the experiment. They logged into the experimental website and browsed the experiment website afterward. Each subject was randomly assigned to a TN or CF group by the experimental system.

Step 2: The experimental system presented six products and associated information recommended by TN or CF (three bottles of healthy drink for experience goods and three magazines for search goods). The recommendation order was random in order to avoid the possible order effect. After viewing the recommendation messages, the 
subject chose the most favored product and put it into the shopping cart to complete his shopping mission.

Step 3: The subject filled out the purchase intention for each of the recommended products after completing step 2.

Step 4: After completing the first module of ordering recommended products, the subject was arranged to try the recommended products outside the experiment lab in the second module.

Step 5: After experiencing with the recommended products, the subject was asked to full out the postpurchase questionnaire. Those who completed the experiment received a monetary reward of US\$3.

\section{Research Results and Discussions}

\section{Sample and Descriptive Statistics}

Among the 108 subjects who participated in our experiment, there were more females $(55.56 \%)$ than males $(44.44 \%)$. The majority had college or graduate degrees $(57 \%$ and $42 \%$ respectively). Most of them had 6 to 10 years' Internet experience. The average daily Internet using time was around 5 hours, and about half of the subjects had eshopping experience. Most subjects read less than 2 magazines per week, and had less than one healthy drink.

The means and standards deviation of the purchase intention and disconfirmation in different experimental contexts are shown in Table 1 and Table 2. The measurement scale of purchase intention is from 1 (weakest) to 7 (strongest). Higher number indicates stronger purchase intention or disconfirmation.

\section{Table 1 - Descriptive Statistics of Purchase Intention}

\begin{tabular}{|l|c|c|}
\hline \multirow{2}{*}{ Product type } & \multicolumn{2}{|c|}{ Recommendation approach } \\
\cline { 2 - 3 } & $\mathrm{TN}(\mathrm{n}=57)$ & $\mathrm{CF}(\mathrm{n}=51)$ \\
\hline Experience goods & $4.666(0.912)$ & $4.716(1.029)$ \\
\hline Search goods & $4.827(1.073)$ & $4.418(0.934)$ \\
\hline Note: mean (standard deviation) & \multicolumn{2}{|}{} \\
\hline
\end{tabular}

\section{Table 2 - Descriptive Statistics of Disconfirmation}

\begin{tabular}{|l|c|c|}
\multirow{2}{*}{ Product type } & \multicolumn{2}{|c|}{ Recommendation approach } \\
\cline { 2 - 3 } & $\mathrm{TN}(\mathrm{n}=57)$ & $\mathrm{CF}(\mathrm{n}=51)$ \\
\hline Experience goods & $1.189(0.696)$ & $0.838(0.644)$ \\
\hline Search goods & $0.702(0.465)$ & $0.762(0.610)$ \\
\hline Note: mean (standard deviation) & \multicolumn{2}{|}{} \\
\hline
\end{tabular}

\section{Data Analysis}

The collected data were further analysed with ANCOVA to test our hypotheses. The results are provided below.

(1) Effects on purchase intention

Table 3 shows the ANCOVA result of purchase intention, which indicates that (a) the main effects of recommendation approach and product type are not statistically significant and (b) the interaction effect of recommendation approaches and product types is significant. Hence, $\mathrm{H} 1$ and $\mathrm{H} 3$ are not supported, but $\mathrm{H} 5$ is supported. The covariate variable, self-monitoring, is not statistically significant either. 
Since the interaction effect is significant, it is interesting to look into the effects under different settings. As shown in Figure 2(a), the average purchased intention toward experience goods was higher than that of search goods when the product was recommended by the CF approach, but the average purchased intention toward search goods was higher than that of experience goods when the product was recommended by the TN approach. However, the main effect difference between TN and CF is not statistically significant. Figure 2(b) shows that the difference between recommendation approaches is significant for search goods $(p<0.05)$, but not significant for experience goods. This finding indicates that Top-N outperformed CF when the recommended products were search goods. This result contradicts the hypothesis $\mathrm{H} 1$ and previous findings by Senecal and Nantel (2004) that consumers prefer experience goods. This implies that the herd effect exists for search goods whose product quality can be assessed by their functional descriptions. For recommending search goods, messages about the popularity of products seem to be more convincing for buyers than those about personal association. It is better to adopt the TN approach for recommending search goods and the CF approach for recommending experience goods to gain a higher intention to purchase.

\section{Table 3 - Results of Mixed Model ANOVA (DV: Purchase intention; $\mathbf{n}=108$ )}

\begin{tabular}{|l|c|c|c|c|}
\hline Source & Sum of Square & $\mathrm{df}$ & Mean Square & $\mathrm{F}$ \\
\hline Self-monitoring (covariate) & 1.766 & 1 & 1.766 & 1.413 \\
\hline Recommendation Approach & 1.717 & 1 & 1.717 & 1.374 \\
\hline Product Type & 0.173 & 1 & 0.173 & 0.247 \\
\hline $\begin{array}{l}\text { Recommendation Approach x Product } \\
\text { Type }\end{array}$ & 2.818 & 1 & 2.818 & $4.024^{*}$ \\
\hline Group & 204.740 & 210 & & \\
\hline$\quad$ Subjects & 131.223 & 105 & 1.250 & \\
\hline$\quad$ Error & 73.517 & 105 & 0.700 & \\
\hline Total & 211.650 & 214 & & \\
\hline${ }^{*} p<0.05$ &
\end{tabular}

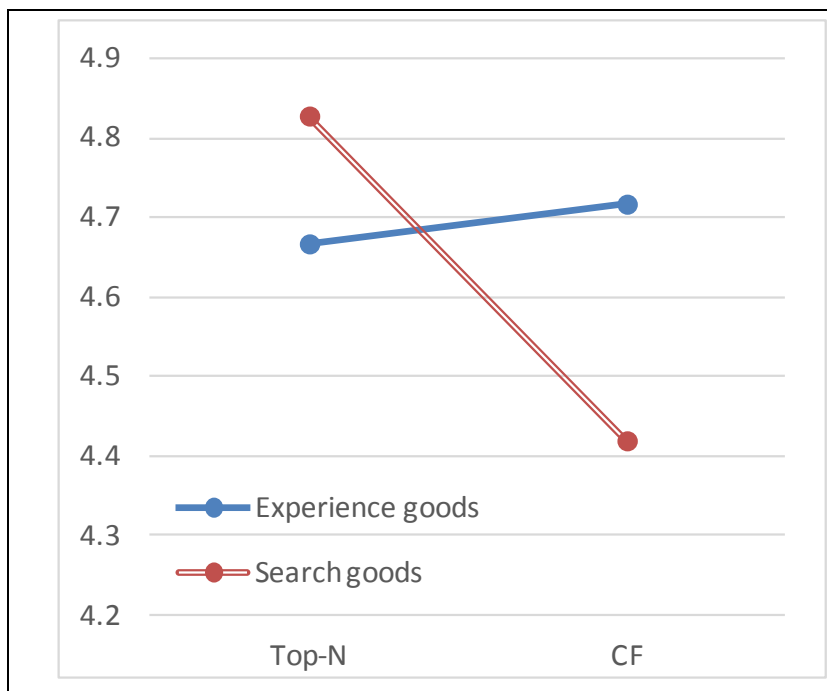

(a) Cell means plot by recommendation approaches

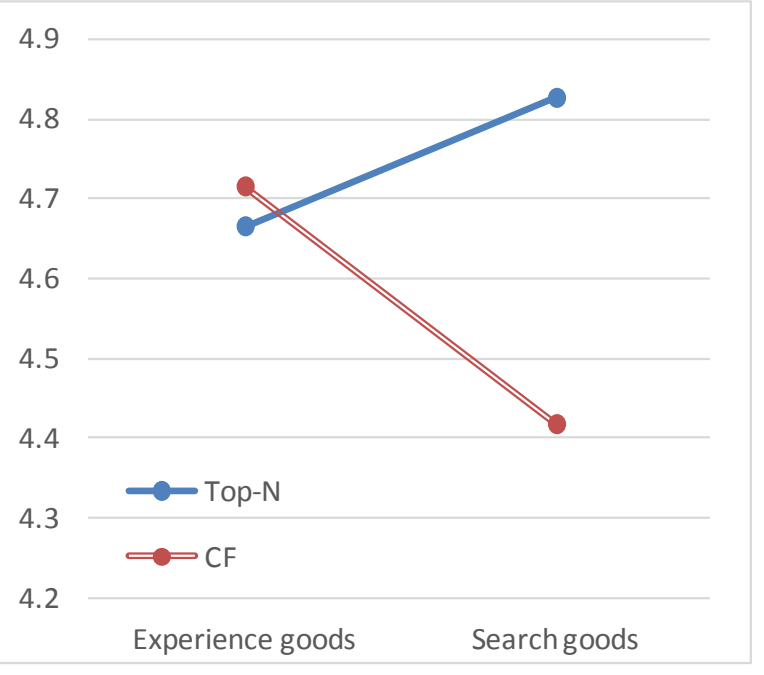

(b) Cell means plot by product types

\section{Figure 2 - Interaction Plot for Purchase Intention}




\section{(2) Effects on Disconfirmation}

Table 4 shows the ANCOVA result of disconfirmation, which indicates that (a) the effect of product type is statistically significant $(p<0.05)$, (b) the interaction of recommendation approach and product type is statistically significant $(p<0.05)$, and (c) self-monitoring is statistically significant $(p<$ 0.05). In other words, $\mathrm{H} 6$ is supported. However, since the interaction effect is statistically significant, the effect of product type should be discussed by different recommendation approaches.

Figure 3 shows that the experience goods recommended by the TN approach resulted in a significantly higher level of disconfirmation after consumption, and the high disconfirmation on experience goods existed only when they were recommended by the TN approach, not when they were recommended by the CF approach. In other words, it would be better to adopt the CF approach for experience goods and the TN approach for search goods to reduce the disconfirmation after consumption. The significance of self-monitoring indicates that the post-consumption disconfirmation is affected by consumers' personality. This is reasonable as those with high selfmonitoring may be more flexible in their perceptions.

\section{Table 4 - Results of Mixed Model ANOVA (DV: Disconfirmation; $\mathbf{n = 1 0 8 )}$}

\begin{tabular}{|l|c|c|c|c|}
\hline Source & Sum of Square & $\mathrm{df}$ & Mean Square & $\mathrm{F}$ \\
\hline Self-monitoring (covariate) & 2.522 & 1 & 2.522 & $5.557^{*}$ \\
\hline Recommendation Approach & 1.137 & 1 & 1.137 & 2.505 \\
\hline Product Type & 1.604 & 1 & 1.604 & $5.985^{*}$ \\
\hline $\begin{array}{l}\text { Recommendation Approach x Product } \\
\text { Type }\end{array}$ & 2.27 & 1 & 2.27 & $8.47^{*}$ \\
\hline Group & 78.579 & 212 & & \\
\hline Subjects & 47.659 & 106 & 0.454 & \\
\hline$\quad$ Error & 28.142 & 106 & 0.268 & \\
\hline Total & 86.11 & 216 & & \\
\hline${ }^{*} p<0.05$ & \multicolumn{5}{l}{} \\
\hline
\end{tabular}

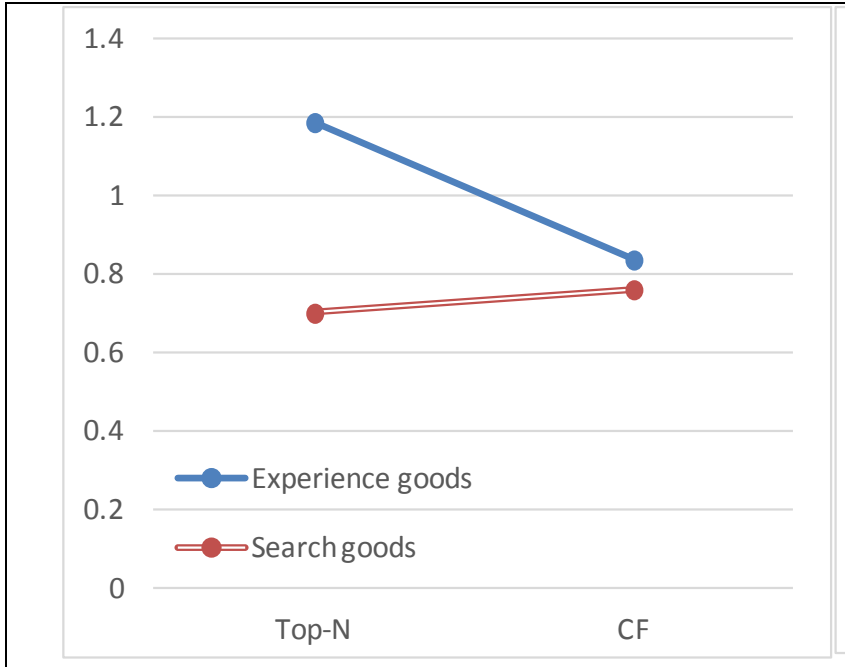

(a) Cell means plot by recommendation approaches

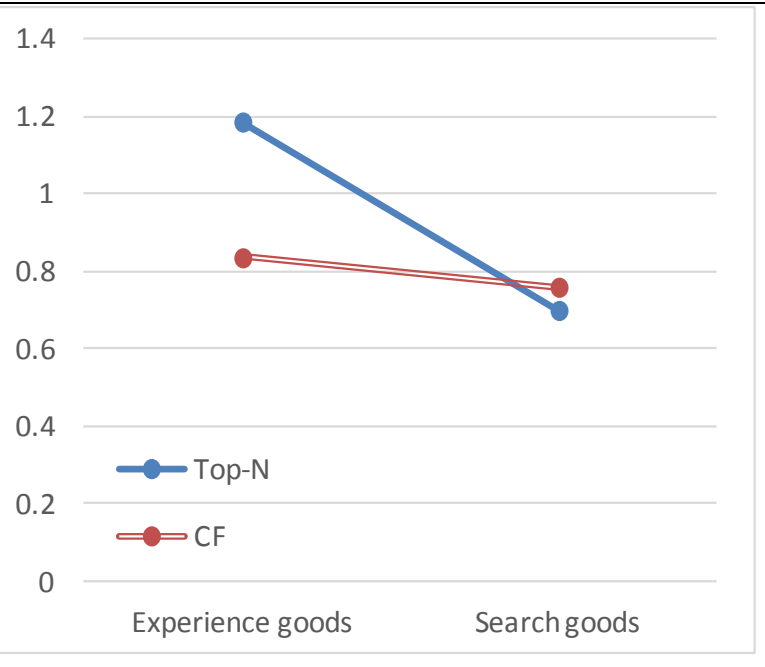

(b) Cell means plot by product types

\section{Figure 3 - Interaction Plot for Disconfirmation}




\section{Summary and Conclusion}

Product recommendation is a common practice in electronic commerce. In this study, we investigated the effect of recommendation approaches and product types on purchase intention and postconsumption disconfirmation. A laboratory was designed and conducted. Our findings indicate that the purchase intention is not affected by product type or recommendation approach alone. However, their interactions do have significant effects on both purchase intention and post-consumption disconfirmation. Table 5 summarizes our hypotheses and results.

More specifically, the Top- $\mathrm{N}$ approach is better for recommending search goods whereas the CF approach is better for experience goods in generating higher purchase intention. When Top- $\mathrm{N}$ is applied to experience goods, there is no increase in purchase intention but may increase the expectation disconfirmation. As the Top-N approach is non-personal popularity-based recommendation method and the CF approach is personalized recommendation, our findings show that previous literature on the effect of personalized recommendation may need further investigation.

\begin{tabular}{|c|c|c|}
\hline ID & Hypothesis & Result \\
\hline $\mathrm{H} 1$ & $\begin{array}{l}\text { Purchase intention of the products recommended by CF is } \\
\text { higher than that of the products recommended by TN }\end{array}$ & Not supported \\
\hline $\mathrm{H} 2$ & $\begin{array}{l}\text { Disconfirmation of products recommended by CF is lower } \\
\text { than that of products recommended by TN }\end{array}$ & Not supported \\
\hline $\mathrm{H} 3$ & $\begin{array}{l}\text { Purchase intention of recommended search goods is higher } \\
\text { than that of experience goods }\end{array}$ & Not supported \\
\hline $\mathrm{H} 4$ & $\begin{array}{l}\text { Disconfirmation of recommended search goods is lower } \\
\text { than that of experience goods }\end{array}$ & Not supported \\
\hline H5 & $\begin{array}{l}\text { Significant interaction effect between recommendation } \\
\text { approach and product type exists on purchase intention }\end{array}$ & Supported \\
\hline $\mathrm{H} 6$ & $\begin{array}{l}\text { Significant interaction effect between recommendation } \\
\text { approach and product type exists on consumers' } \\
\text { disconfirmation. }\end{array}$ & Supported \\
\hline
\end{tabular}

Our findings have a few limitations due to research method and subject selection. First, the behavior observed in the experiment may not be the same as that in the real world. This is the restriction of the research method. More studies using other research methods may help to evaluate whether our findings will still hold. Second, the majority of our subjects in the experiment were students. Although those student subjects were online consumers and had adequate Internet experience, their behaviors may be different from older people with a long-term job and thus reduce the generalizability of our findings. This may be mitigated by more studies on different types of consumers.
The selected experimental product may be another limitation. We chose three experience and three search products among many different items. However, attributes consumers consider in purchasing different items are different

The contribution of this research is two-fold. Theoretically, our findings show that personalized recommendation may not always be effective as argued in previous literature. Indeed, the effect of personalized recommendation may need to be divided into two effects: personalization and recommendation. The effect observed in some previous research may be due to recommendation, rather than 
personalization. Simple approach such as the popularity-based Top- $\mathrm{N}$ approach may be already adequate for most products. Future research may develop more theories and conduct more studies to explore this direction.

The second contribution is that practitioners may take advantage of our findings to choose proper approaches for cross-selling their products online. Our findings indicate significant interaction effects exist on both purchase intention and post-consumption disconfirmation. Although high purchase intention is likely to lead revenue increase, high expectation disconfirmation may reduce customer loyalty and hurt the longterm customer relationship. Managers need to be careful in balancing these two aspects when they choose the recommendation approach.

\section{Acknowledgements}

This work was supported in part by the Ministry of Science and Technology of the Republic of China under the grant MOST 103-2410-H-030-087-MY3 and NSC 952416-H-126-014.

\section{References}

Aggarwal, P. and Vaidyanathan, R. (2005). "Perceived Effectiveness of Recommendation Agent Routines: Search vs. Experience Goods," International Journal of Internet Marketing and Advertising, 2(1-2), pp.38-55.

Anderson, R.E. (1973). "Consumer Dissatisfaction: The Effect of Disconfirmed Expectancy on Perceived Product Performance," Journal of Marketing Research, 10 (1), pp.38-44.

Benlian, A., Titah, R. and Hess, T. (2012). "Differential Effects of Provider Recommendations and Consumer
Reviews in E-Commerce Transactions: An Experimental Study," Journal of Management Information Systems, 29(1), pp.237-272.

Cadotte, E.R., Woodruff, R.B. and Jenkins, R.L. (1987). "Expectations and Norms in Models of Consumer Satisfaction," Journal of Marketing Research, 24(3), pp.305-314.

Chen, D.N., Hu, P. J.H., Kuo, Y.R. and Liang, T.P. (2010). "A Web-Based Personalized Recommendation System for Mobile Phone Selection: Design, implementation, and evaluation," Expert Systems with Applications, 37(12), pp.8201-8210.

Chiang, K.P. and Dholakia, R.R. (2003). "Factors Driving Consumer Intention to Shop Online: An empirical investigation," Journal of Consumer Psychology, 13(1-2), pp.177-183.

Dodds, W.B., Monroe, K.B. and Grewal, D. (1991). "Effects of Price, Brand, and Store Information on Buyers' Product Evaluations," Journal of Marketing Research, 28(3), pp.307-319.

Fishbein, M. and Ajzen, I. (1975). Belief, Attitude, Intention and Behavior: An introduction to theory and research. Addison-Wesley: Massachusetts.

Grewal, D., Krishnan, R., Baker, J. and Borin, N. (1998). "The Effect of Store Name, Brand Name and Price Discounts on Consumers' Evaluations and Purchase Intentions," Journal of Retailing, 74(3), pp.331-352.

Gupta, B., Lai, F.C., Pal, D., Sarkar, J. and Yu, C.M. (2004). "Where to Locate in a Circular City?," International Journal of Industry Organization, 22(6), pp.759-782.

Im, I. and Hars, A. (2001). "Finding Information Just for You: Knowledge reuse using collaborative filtering systems," Proceedings of the TwentySecond International Conference on Information Systems, pp.349-360. 
Köhler, C., Breugelmans, E. and Dellaert, B.G.C. (2011). "Consumer Acceptance of Recommendations by Interactive Decision Aids: The joint role of temporal distance and concrete versus abstract communications," Journal of Management Information Systems, 27(4), pp.231-260.

Li, S.S. and Karahanna, E. (2015). "Online Recommendation Systems in a B2C E-Commerce Context: A review and future directions," Journal of the Association for Information Systems, 16(2), Article 2.

Liang, T.P., Lai, H.J. and Ku, Y.C. (2006). "Personalized content recommendation and User Satisfaction: Theoretical Synthesis and Empirical Findings," Journal of Management Information Systems, 23(3), pp.45-70.

Liang, T.P., Yang, Y.F., Chen, D.N. and Ku, Y.C. (2008). "A Semantic-Expansion Approach to Personalized Knowledge Recommendation," Decision Support Systems, 45(3), pp.401-412.

McKinney, V., Yoon, K. and Zahedi, F. (2002). "The Measurement of WebCustomer Satisfaction: An expectation and disconfirmation approach," Information Systems Research, 13(3), pp.296-315.

Mudambi, S.M. and Schuff, D. (2010). "What Makes a Helpful Online Review? A study of customer reviews on amazon.com," MIS Quarterly, 34(1), pp.185-200.

Nelson, P. (1970). "Information and Consumer Behaviour," Journal of Political Economy, 78(2), pp.311-329.

Schafer, J.B., Konstan, J. and Riedl, J. (1999). "Recommender Systems in ECommerce," Proceedings of the first ACM conference on Electronic Commerce, pp.158-166.
Schiffman, L.G. and Kanuk, L.L. (1999). Consumer Behavior, 7th Edition, Pearson Education: New Jersey.

Senecal, S. and Nantel, J. (2004). "The Influence of Online Product Recommendations on Consumers' Online Choices," Journal of Retailing, 80(2), pp.159-169.

Serenko, A. and Stach, A. (2009). "The Impact of Expectation Disconfirmation on Customer Loyalty and Recommendation Behavior: Investigating online travel and tourism services," Journal of Information Technology Management, 20(3), pp.26-41.

Snyder M. (1974). "Self-monitoring of Expressive Behaviour," Journal of Personality and Social Psychology, 30(4), pp.526 - 537.

Snyder, M. and Gangestad, S. (1986). "On the Nature of Self-Monitoring: Matters of assessment, matters of validity," Journal of Personality \& Social Psychology, 51(1), pp. 125-139.

Snyder, R.A. and Williams, R.R. (1982). "Self Theory: An integrative theory of work motivation," Journal of Occupational Psychology, 55(4), pp.257-267.

Tan, C.W., Benbasat, I. and Cenfetelli, R.T. (2016). "An Exploratory Study of The Formation and Impact of Electronic Service Failures," MIS Quarterly, 40(1), pp.1-29.

Venkatesh, V. and Goyal, S. (2010). "Expectation Disconfirmation and Technology Adoption: Polynomial modeling and response surface analysis," MIS Quarterly, 34(2), pp.281-303.

Wang J.C. and Lin, J.P. (2003). "Are Personalization Systems Really Personal? - Effects of conformity in reducing information overload," Proceedings of the 36th Hawaii 
International Conference on System Sciences.

Wang, W. and Benbasat, I. (2007). "Recommendation Agents for Electronic Commerce: Effects of explanation facilities on trusting beliefs," Journal of Management Information Systems, 23(4), pp.217246.

Xiao, B. and Benbasat, I. (2007). "ECommerce Product Recommendation Agents: Use, Characteristics, and Impact," MIS Quarterly, 31(1), pp. 137-209.
Yu, T., Benbasat, I. and Cenfetelli, R. (2011). "Toward Deep Understanding of Persuasive Product Recommendation Agents," Proceedings of International Conference on Information Systems.

Zhang, T., Agarwal, R. and Lucas, H.C. (2011). "The Value of IT-enabled Retailer Learning: Personalized product recommendations and customer store loyalty in electronic markets," MIS Quarterly, 35(4), pp.859-881. 


\section{Appendix A: Sample Screens of the Experimental System}

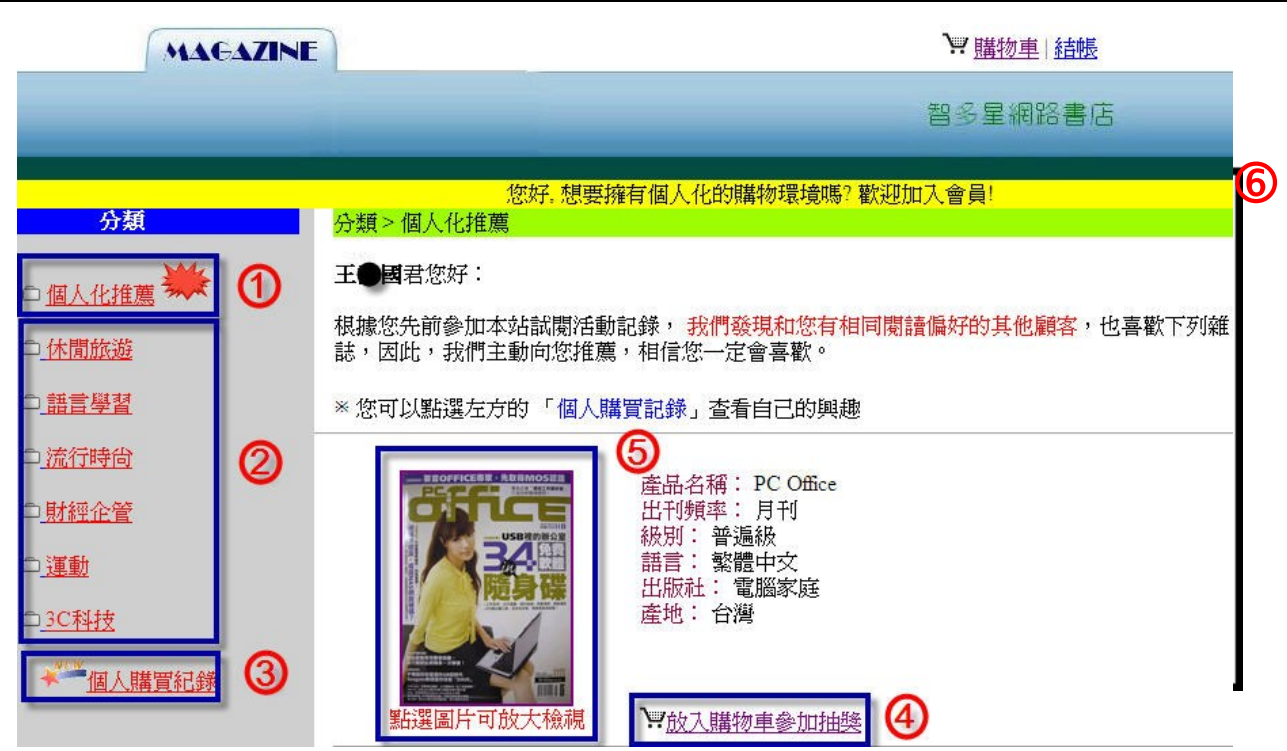

\section{Figure A - Sample screen of recommended magazine (Search goods)}

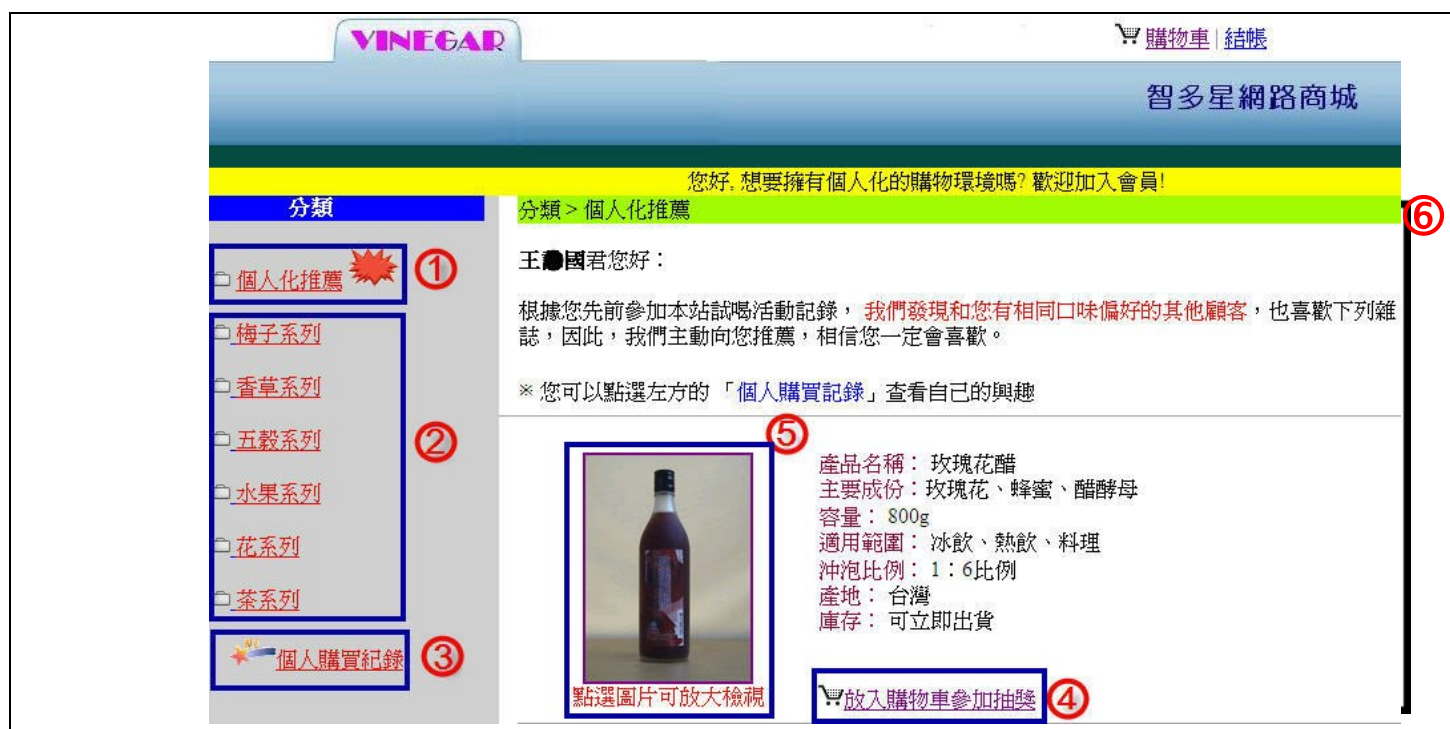

\section{Figure B - Sample screen of recommended healthy drink (Experience goods)}

Note:
(1) Recommendation for subject
(2) Product category
(3) Order history
(4) Shopping cart
(5) Click to enlarge product photo
(6) Recommendation information 


\section{Appendix B: The Measurements of Purchase Intention and Self- monitoring}

\begin{tabular}{|c|c|c|}
\hline Construct & Item & Reference \\
\hline $\begin{array}{l}\text { Purchase } \\
\text { Intention }\end{array}$ & $\begin{array}{l}\text { The likelihood of purchasing this product is very high. } \\
\text { The probability that I would consider buying this product is } \\
\text { very high. } \\
\text { My willingness to buy this product is very high. }\end{array}$ & $\begin{array}{l}\text { Dodds et al. (1991); } \\
\text { Grewal et al. (1998) }\end{array}$ \\
\hline $\begin{array}{l}\text { Self- } \\
\text { monitoring* }\end{array}$ & $\begin{array}{l}\text { - I find it hard to imitate the behavior of other people. (F) } \\
\text { At parties and social gatherings, I do not attempt to do or say } \\
\text { things that others will like. (F) } \\
\text { - I can only argue for ideas which I already believe. (F) } \\
\text { I can make impromptu speeches even on topics about which } \\
\text { I have almost no information. (T) } \\
\text { I guess I put on a show to impress or entertain others. (T) } \\
\text { I would probably make a good actor. (T) } \\
\text { In different situations and with different people, I often act like } \\
\text { very different persons. (T) } \\
\text { I am not particularly good at making other people like me. (F) } \\
\text { I am not always the person I appear to be. (T) } \\
\text { order to please someone or win their favor. (F) } \\
\text { I have considered being an entertainer. (T) } \\
\text { I have never been good at games like charades or } \\
\text { improvisational acting. (F) } \\
\text { I have trouble changing my behavior to suit different people } \\
\text { and different situations. (F) } \\
\text { At a party I let others keep the jokes and stories going. (F) } \\
\text { I feel a bit awkward in public and do not show up quite as } \\
\text { well as I should. (F) } \\
\text { I I can look anyone in the eye and tell a lie with a straight face } \\
\text { (if for a right end). (T) } \\
\text { I may deceive people by being friendly when I really dislike } \\
\text { them. (T) }\end{array}$ & $\begin{array}{l}\text { Snyder and } \\
\text { Gangestad (1986), } \\
\text { p. } 137 \\
\\
\end{array}$ \\
\hline
\end{tabular}

Note: Keying is given by either $\mathrm{T}$ (true) or $\mathrm{F}$ (false) in parentheses following item. High self-monitoring individuals tend to answer in the keyed direction; low self-monitoring individuals tend to answer in the alternative direction. 


\section{About the Authors}

Yi-Cheng $\mathrm{Ku}$ is an Associate Professor of Business Administration at $\mathrm{Fu}$ Jen Catholic University in Taiwan. He received his Ph.D. in Information Management from National Sun Yat-sen University. In 2009-2010, he was a Fulbright visiting scholar at the Scheller College of Business, Georgia Institute of Technology. His research interests include recommendation systems, information system adoption and diffusion, and service science. His papers have appeared in Journal of Management Information Systems (JMIS), Decision Support Systems (DSS), Information \& Management (I\&M), Computers in Human Behavior, International Journal of Business, International Journal of Medical Informatics, Journal of Electronic Commerce Research, and various conference proceedings.
Yi-Ming Tai is an Associate Professor of Information Management at National Pingtung University in Taiwan. His research focuses on electronic commerce, enterprise resource planning, supply chain management, and product lifecycle management. He has published with Industrial Management and Data Systems, International Journal of Electronic Commerce, International Journal of Logistics: Research and Applications, International Journal of Production Research, and Journal of Electronic Commerce Research.

Chih-Hung Chan received his Master's degree in Computer Science and Information Management from the Providence University. His research interests include e-commerce and personalized service. 